\title{
Dry Powder Inhalers: Particle Size and Patient-Satisfaction
}

\author{
S. K. Jindal, K. K. Pandey ${ }^{1,2}$, P. P. Bose ${ }^{3}$
}

Jindal Clinic, Emeritus Professor, Department of Pulmonary Medicine, Post Graduate Institute of Medical Education and Research, Chandigarh, ${ }^{1}$ Department of Pulmonology, Yashoda Super Speciality Hospital, Kaushambi, Ghaziabad, Uttar Pradesh, ²Department of Pulmonology, Galaxy Hospital and Institute of Pulmonology, ${ }^{3}$ President Saans Foundation and Senior Consultant, National Heart Institute, Delhi, India

\section{Abstract}

Inhalational route is the cornerstone for drug delivery in asthma. Dry powder inhalers efficiently deliver drug particles to lungs depending on patients' breath actuation and without using propellants. Drug delivery in lungs is dependent primarily on particle size distribution of the formulation. Several studies have proved that drug particles $1-3 \mu \mathrm{m}$ in size provide optimum efficacy with minimum adverse events. Particles $>3 \mu \mathrm{m}$ are deposited in the oropharynx and those $<1 \mu \mathrm{m}$ are exhaled. However, these fine particles might not be felt in the mouth due to which patients may feel that appropriate amount of drug was not dispensed. This perception may negatively influence patient satisfaction and confidence on the device. The patient education on the absence of mouthfeel is thus essential. Treating physicians should provide optimum patient counseling and education addressing the importance of particle size for desired clinical effects.

Keywords: Asthma, chronic obstructive pulmonary disease, dry powder inhaler, inhalational devices, mouthfeel, particle size, patient education

\section{INTRODUCTION}

Chronic obstructive pulmonary disease (COPD) and asthma are leading causes of mortality and morbidity; in 2015, COPD and asthma caused 3.2 million and 0.4 million deaths, respectively. In 2002, COPD ranked $8^{\text {th }}$ and asthma ranked $23^{\text {rd }}$ as causes of disease burden. ${ }^{[1]}$ COPD now ranks as the second leading individual cause of disease burden in India. ${ }^{[2]}$ Pulmonary drug delivery by the inhaled route is the mainstay of treatment for asthma and COPD. ${ }^{[3]}$ The major advantages include lower dose requirement for intended clinical efficacy, faster onset of action (because of topical application), and circumvention of first-pass metabolism. The devices routinely used for delivering inhalation drugs are classified into pressured metered dose inhalers (pMDIs), dry powder inhalers (DPIs), and nebulizers. ${ }^{[4]}$

\section{TyPeS OF DRUg Delivery}

\section{Inhalation devices}

Nebulizers are the oldest available inhalational devices, where the drug, in a solution or suspension, is packed usually into single-use containers and is nebulized into fine droplets. Jet nebulizers, ultrasonic nebulizers, and vibrating mesh

\begin{tabular}{|l|l|}
\hline \multicolumn{2}{|c|}{ Access this article online } \\
\hline Quick Response Code: & Website: \\
& www.ijrc.in \\
\cline { 2 - 2 } & \\
&
\end{tabular}

nebulizers are some types of nebulizers available in the market. Nebulizers can be used by patients who are unable to coordinate breathing, such as geriatric and pediatric patients, and where large drug doses are required. ${ }^{[5,6]}$

pMDIs contain the drug in a suspension or solution formulation, which is released as aerosol upon combination with high pressure liquefied propellants, usually chlorofluorocarbons or hydrofluoroalkanes (HFA-134a and HFA 227). Several pMDIs are available, such as Proventil ${ }^{\circledR}$, Ventolin $^{\circledR}$, Qvar $^{\circledR}$, Flovent $^{\circledR}$, and Advair ${ }^{\circledR} .{ }^{[3]}$ pMDIs are easy to use, portable, inexpensive, low maintenance devices and can deliver the drug into deep regions of the respiratory tract; however, coordination between actuation and inhalation is required.

DPIs are generally single-dose devices containing the drug in a capsule form or multi-dose devices storing the drug in

Address for correspondence: Dr. S. K. Jindal, Jindal Clinic, Emeritus Professor, Post Graduate Institute of Medical Education and Research, Chandigarh, India. E-mail: dr.skjindal@gmail.com

This is an open access journal, and articles are distributed under the terms of the Creative Commons Attribution-NonCommercial-ShareAlike 4.0 License, which allows others to remix, tweak, and build upon the work non-commercially, as long as appropriate credit is given and the new creations are licensed under the identical terms.

For reprints contact:WKHLRPMedknow_reprints@wolterskluwer.com

How to cite this article: Jindal SK, Pandey KK, Bose PP. Dry powder inhalers: Particle size and patient-satisfaction. Indian J Respir Care 2021;10:14-8.

Received: $19-11-2019$

Accepted: $02-06-2020$

Revised: 13-05-2020 Published: 31-01-2021 
a bulk reservoir with a metering valve. Another type of DPI is a multi-dose device with individual doses inside. DPIs are easier to use than pMDIs as they are breath-actuated and use the energy from a person's inhalation to de-aggregate the particles into smaller particles.

The four main DPI systems are a capsule-based single-dose device, where patients load a capsule containing the powered formulation into the device before each use; disposable devices containing a premetered single dose; multiple-dose inhalers that have a built-in mechanism to meter a single dose from a reservoir with each actuation; and multiple-dose inhalers with individual doses packed in the device. ${ }^{[7-12]}$ Figure 1 shows several subtypes of DPIs. Table 1 shows the advantages and disadvantages of nebulizers, DPIs, and pMDIs.

\section{Dry powder inhalers}

\section{Development and current scenario}

The idea of DPIs was patented by Vincent Alfred Newton in

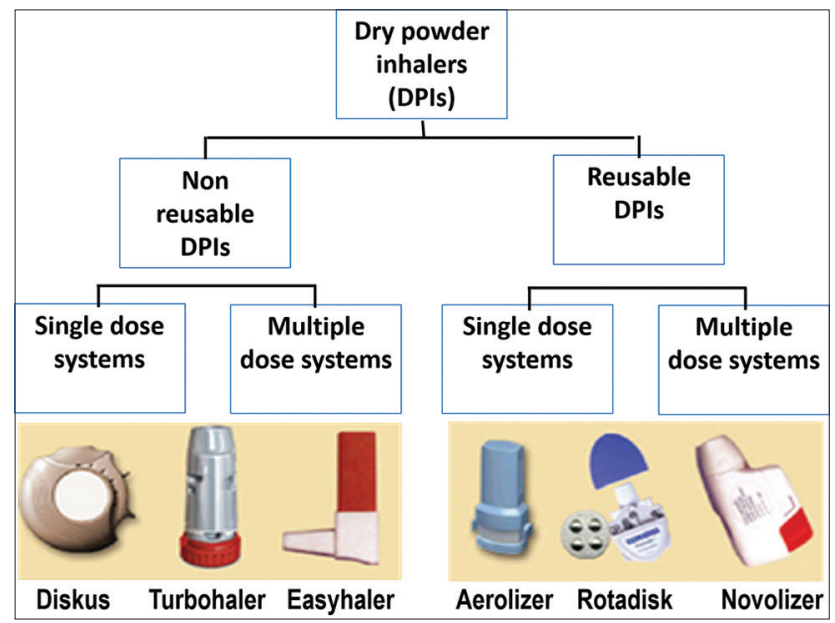

Figure 1: Types of dry powder inhalers ${ }^{[10]}$ the mid-eighteenth century, but the first DPI (Aerohaler ${ }^{\circledR}$ ) was launched in 1948, approximately 100 years after the patent. DPIs are formulated to carry the drug alone or in combination with an inactive excipient such as lactose. Before 2010, all DPIs used the breath-actuated technique for delivering fine drug particles in the respiratory system. However, the breath-actuated technique does not generate enough flow rate for extracting the dose and good powder dispersion and does not achieve the desired therapeutic effect.

Battery-operated DPIs are advantageous as they have a battery-operated propellant or use pressured air from a hand piston for drug dispersion. They deliver flow rate-independent fine particle aerosol. ${ }^{[9]}$ Currently, the mainstream developments that distinguish earlier and present DPIs comprise overcoming the weaknesses in the earlier design concepts, particle engineering, understanding pulmonary drug deposition and distribution from DPIs. ${ }^{[9]}$

\section{Effectiveness of Dry Powder Inhalers}

The effectiveness of DPIs is dependent on the device design. Drug delivery into lungs is determined by several factors such as aerodynamic particle size distribution, inspiratory flow rate, airway geometry, and patient education and training. DPIs require a higher inhalation flow rate, usually higher than $60 \mathrm{~L} / \mathrm{min}$, which helps in de-aggregating and dispersing the drug powder. In case of airway geometry, the usual distribution of drug particles from DPIs occur in a 1:1:1 ratio among conducting (upper) airways, intermediate (transitional) airways, and peripheral (lower) airways.

Usmani et al. observed similar distribution, with a flow rate of $30-67 \mathrm{~L} / \mathrm{min} \cdot{ }^{[13]}$ However, as the airway surface area increases toward the alveoli, and approximately $95 \%$ of the lung surface area is within the peripheral airways, the actual drug concentration in the peripheral airways decreases by a factor of 100 . This factor

Table 1: Advantages and disadvantages of nebulizers, pressurized metered dose inhalers, and dry powder inhalers ${ }^{[10]}$

\begin{tabular}{lll}
\hline Inhaler & Formulation & Advantages \\
\hline $\begin{array}{l}\text { Pressurized metered dose } \\
\text { inhaler (pMDI) }\end{array}$ & $\begin{array}{l}\text { Drug suspended or dissolved } \\
\text { in propellant (with surfactant } \\
\text { and co-solvent) }\end{array}$ & $\begin{array}{l}\text { Portable and compact } \\
\text { Multi-dose device } \\
\end{array}$ \\
& $\begin{array}{l}\text { Relatively inexpensive } \\
\text { Cannot contaminate contents }\end{array}$ \\
$\begin{array}{l}\text { Dry powder inhaler } \\
\text { (DPI) }\end{array}$ & $\begin{array}{l}\text { Available for most inhaled medications } \\
\text { drug alone, drug/excipient } \\
\text { particles }\end{array}$ & $\begin{array}{l}\text { Portable and compact } \\
\text { Breath-actuated (no coordination needed) }\end{array}$ \\
& & Does not contain propellants
\end{tabular}

$\begin{array}{ll}\text { Nebulizer } & \begin{array}{l}\text { Aqueous solution or } \\ \text { suspension }\end{array}\end{array}$
May be used at any age

No specific inhalation technique required

Vibrating mesh is portable and does not require an outside energy source

May dispense drugs not available with pMDIs or DPIs

\section{Disadvantages}

Contains propellants

Not breath-actuated

Many patients cannot use it correctly

High oropharyngeal deposition

Requires a minimum inspiratory flow

May not be appropriate for emergency situations

Many patients cannot use it correctly

Most types are moisture sensitive

Jet and ultrasonic nebulizers require an outside energy source

Treatment times can be long

Performance varies between nebulizers

Jet nebulizers cannot aerosolize a certain

volume of solution

Risk of bacterial contamination

Newer nebulizers are expensive 
is clinically relevant for drugs such as corticosteroids that target smaller airways, but not for beta-blockers or anticholinergics that target the larger airways. ${ }^{[14-16]}$

Aerodynamic particle size determines the site and extent of particle deposition. Particle size is an important criterion for the success of DPIs. For an optimum pharmacodynamic effect, a particle size between 1 and $3 \mu \mathrm{m}$ is most suitable, as particles $<1 \mu \mathrm{m}$ are inevitably exhaled and those $>5 \mu \mathrm{m}$ are deposited in the oropharynx..$^{[11,17]}$ Drugs that reach the alveoli have higher chances of getting absorbed into systemic circulation and have increased potential for adverse events. Therefore, optimum topical effect requires a balance between inspiration and particle size. Engineering Drug Particles for Optimal Lung Deposition Pulmonary drug delivery is more complex than oral drug delivery. It requires a delivery system that can generate an appropriate particle size at the intended flow rate so that drug particles can reach the lower respiratory tract and lungs and create an optimal effect.

Aerodynamic diameter is a prime factor responsible for this process. Particle size measurements for inhaled DPI and pMDI steroids along with reported lung deposition values from literature reveal a median mass aerodynamic diameter of $>2.6 \mu \mathrm{m}$. Lung deposition values with larger drug particles appeared to be not $>20 \%$, with an oropharyngeal deposition of $80 \%$ to $90 \%{ }^{[18-20]}$ Optimal size of the particles in the aerosols depends mainly of the physical properties of carrier particles such as their shape, roughness of their surface, density, and geometric diameter. The effect of these variables on aerosol performance has been studied using three model polystyrene spheres as carriers. The results showed that aerosol performance increased as particle size decreased. ${ }^{[21]} \mathrm{A}$ dose-comparison calculation study showed that compared with an ultrafine-particle inhaled steroid, a large-particle inhaled steroid would take 2.6 times the dose to achieve the same improvement in forced expiratory volume. ${ }^{[22]}$

\section{Effect of Particle Size on Drug Penetration}

Aerodynamic particle size determines drug penetration in the bronchial tree and thus determines the actual dose delivered. Three basic principles are the main determinants of the site and extent of deposition: inertial impaction, sedimentation, and (to a lesser extent) diffusion. ${ }^{[14]}$ During inertial impaction, larger particles are deposited in the proximal airways as the turbulence and velocity are extremely high. Sedimentation allows the particles to deposit on the basis of their weight and gravity and prevents particle exhalation. Diffusion through Brownian motion allows the particles to traverse through the bronchial tree; particles $<1 \mu \mathrm{m}$ are exhaled. ${ }^{[2,13,14]}$ Figure 2 shows the effect of particle size on drug deposition.

Several trials have determined the effect of particle size on drug deposition. ${ }^{[3,12,23]}$ de Boer et al. studied several DPIs and observed that the respirable dose ranges from 1 to $3 \mu \mathrm{m} .{ }^{[2]}$ Laube et al. studied the effect of particle size distribution on lung deposition. Smaller particles achieve greater lung

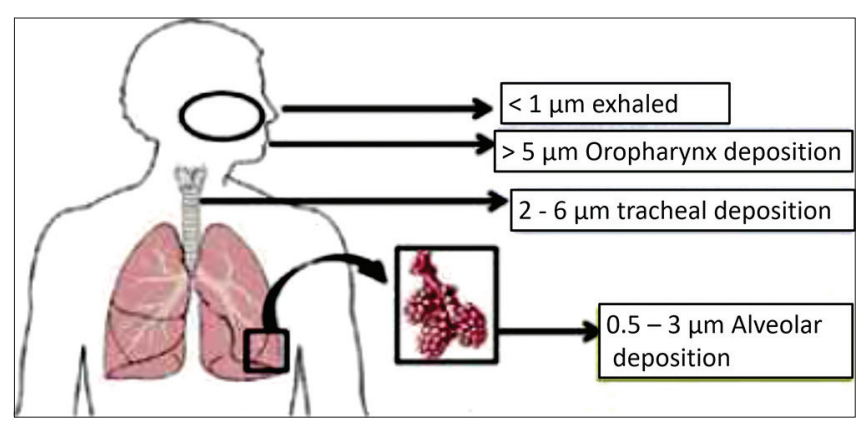

Figure 2: Effect of particle size on drug deposition in the respiratory tract $<1 \mu \mathrm{m}$ Exhaled $>5 \mu \mathrm{m}$ oropharynx deposition 2-6 $\mu \mathrm{m}$ tracheal deposition 0.5-3 $\mu \mathrm{m}$ alveolar deposition recreated from: Demoly et al. ${ }^{[14]}$

deposition with highest being at $1.5 \mu \mathrm{m}$ (56\% lung deposition, distal penetration index 0.79 , and peripheral lung deposition at $25 \%$ ). As the particle size increases, these factors decrease with $46 \%$ lung deposition, 0.36 distal penetration index, and $10 \%$ peripheral lung deposition at $6 \mu \mathrm{m}$.

Increased oropharyngeal losses can be compensated by increasing delivered fine particle dose with increasing flow rate. This helps in more constant lung deposition and more uniform distribution. ${ }^{[24]}$ In patients with asthma, better lung deposition and penetration in distal airways was observed with $1.5-\mu \mathrm{m}$ particles compared with 3 - and $6-\mu \mathrm{m}$ particles. ${ }^{[13,24]}$ Figure 3 shows the percentage drug deposition in lungs per the Usmani et al. (2005) study. However, smaller particles are not felt in the mouth and have no taste, possibly leading to lesser patient satisfaction as there is no mouthfeel of drug.

\section{Effect of Particle Size on Safety and TOLERABILITY}

The oropharyngeal-laryngeal deposition of drug particles is an important concern for all inhaled formulations. Particle size plays an important role in the incidence of adverse events with inhaled corticosteroids. With DPIs, approximately 50\% of the inhaled drug is deposited in the oropharyngeal region. This deposited drug causes several topical adverse events such as caries, oral thrush, and dysphonia. Sometimes, the drug particles are swallowed and enter systemic absorption from the gastrointestinal tract and might cause systemic adverse events. ${ }^{[25]}$

A meta-analysis of 23 studies observed a three-fold increase in the incidence of oral thrush in patients using DPIs. ${ }^{[26]}$ Dekhuijzen et al. conducted a real-life study on the effects of inhaled corticosteroids, drug, dose, and device on the incidence of oral thrush. Overall, the incidence increased with inhaled corticosteroids and was dose dependent for fluticasone propionate/salmeterol therapy. ${ }^{[27]}$ Price et al. observed that direct spraying of the medication into the oral cavity leaves a substantial portion of the dosage on the patient's tongue, which might promote fungal growth on the tongue. ${ }^{[28]}$ Although there is no clear evidence of dental caries caused by antiasthmatic drugs, the lactose content of DPIs might indirectly cause 
Jindal, et al.: DPI - Particle size and patient-satisfaction

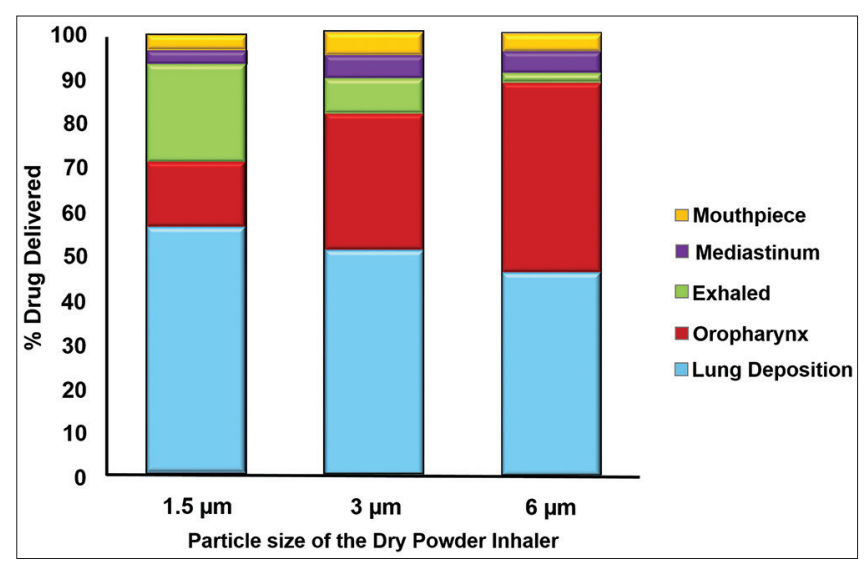

Figure 3: Effect of particle size on percent drug deposition in lungs ${ }^{[12]}$ recreated from: Usmani et al. ${ }^{[13]}$

dental caries. ${ }^{[29]}$ Dysphonia is another local adverse event due to oropharyngeal deposition. ${ }^{[30]}$

The reduced rate of oropharyngeal and laryngeal adverse effects, such as oropharyngeal candidiasis and dysphonia, found with inhaled corticosteroid treatment is probably a consequence of low oropharyngeal deposition seen with DPIs with a lower aerodynamic particle size. ${ }^{[31]}$ Thus, a smaller particle size reduces the risk of oral candidiasis, hoarseness of voice, aftertaste, an effect on the throat (such as cold, dry, or sore), and cough, which are common with bigger particle size.

\section{Drug Not Felt: Optimum Clinical Outcome}

The goal of managing patients with COPD and asthma is gaining control on the symptoms, preventing disease exacerbation, and improving the quality of life. This goal can be achieved by delivering the optimum dose of prescribed drugs to the target site in the respiratory system and preventing drug losses midway. Thus, studies have stressed on the importance of drug availability and administration time; patient age and ability to use the device correctly; convenience; costs; and physician and patient preference while selecting drugs and devices for inhaled formulations. ${ }^{[16,23]}$ Consistency in dose delivery to the lungs is required for efficient therapy and drug safety and tolerability also depend on consistent dose delivery. Consistent dose delivery shows codependency with device characteristics and drug formulation.

Particle size distribution from DPIs plays a significant role in drug deposition in the target areas. The drug dose from DPIs may be substantially lower than expected because of losses in the inhaler, oropharyngeal deposition, and exhalation of very fine particles. The amount of drug deposited in the upper respiratory tract (up to the larynx) and mouth does not contribute to the pharmacological activity of drug. Only the drug available in the lower part of the bronchial tree and alveoli is effective in treating the symptoms of asthma and COPD. ${ }^{[2]}$ Several studies have observed that particle sizes ranging from
1 to $3 \mu \mathrm{m}$ are best suited for lung deposition. Particles $<1$ $\mu \mathrm{m}$ are exhaled through the lungs, and particles $>5 \mu \mathrm{m}$ are deposited in the oropharynx and thus lost to activity. ${ }^{[2,13]}$

Clinical studies have shown that the mouthfeel of particles is dependent on particle size. A study analyzed the effect of particle size on the feel or grittiness of aqueous suspension and found that $<50 \%$ of patients could perceive grittiness when the average particle size was $<10 \mu \mathrm{m} .{ }^{[32]}$ Engelen et al. observed that a particle size of $2 \mu \mathrm{m}$ was responsible for rough to slippery lip-tooth feel that was perceived only when a thin compressed layer was applied on the lips and tongue. ${ }^{[33]}$ Users are able to detect particle size as less as $5.2 \mu \mathrm{m}$ only when the particles are rough or angular in shape. ${ }^{[34]}$ Hence, if the drug particle size in the DPI formulation is $<5 \mu \mathrm{m}(1-3 \mu \mathrm{m})$, the formulation characteristics makes it likely that more drug will be deposited at the target site and there will be less losses due to oropharyngeal deposition. Consequently, there will be less adverse events due to the local action of drugs in the oropharynx.

The patient adherence to treatment is an important factor for the success of inhalational therapy. Adherence is dependent on the ease of use, patient education for application of correct technique, patient satisfaction, and tolerability of drug formulation. ${ }^{[16]}$ In case of a smaller particle size, although tolerability is likely to be higher because of lesser oral adverse events, patient satisfaction might be hampered as the drug is not felt in the mouth. This may also lead to misuse or overuse of the inhaler as the patient may feel that an adequate amount of drug was not dispensed from the device. This ultimately may lead to therapy noncompliance, lack of patient satisfaction, less confidence about the device, and may cause relevant economic losses to the patient and health care industry in general.

Patient awareness and education will be critical in limiting these problems. Patients should be made aware that the optimum drug particle size may not have any taste or mouthfeel. The current guidance also recommends that practitioners should first understand devices that are available to patients, key device characteristics, and how these characteristics might affect patient preference and practice. Health-care practitioners and patient advisors must initiate proper training and counseling for patients at therapy initiation and during therapy.

\section{ConcLusion}

Consistent drug dose to the lungs is mandatory for an adequate and efficient inhalational therapy. The efficiency and safety of pulmonary drug administration through DPIs depend on the aerodynamic size of desired drug particle for optimum drug deposition in the target area. What is "lost" in the mouth- throat region does not contribute to the therapeutic effect and can cause adverse local or systemic side effects. However, fine particle size may not cause sensation or aftertaste, which may lead to patient dissatisfaction or concern. Thus, treating physicians should provide optimum patient counseling and education addressing the importance of particle size for desired clinical effects. 
Jindal, et al.: DPI - Particle size and patient-satisfaction

\section{Acknowledgement}

The authors would like to thank Astra Zeneca Pharma India Ltd., Bengaluru and Prajakta Nachane, from Sciformix Technologies Pvt., Ltd., Mumbai-India, for providing medical writing assistance in the development of this manuscript.

\section{Financial support and sponsorship}

Nil.

\section{Conflicts of interest}

There are no conflicts of interest.

\section{RefERENCES}

1. GBD 2015 Chronic Respiratory Disease Collaborators. Global, regional, and national deaths, prevalence, disability-adjusted life years, and years lived with disability for chronic obstructive pulmonary disease and asthma, 1990-2015: A systematic analysis for the Global Burden of Disease Study 2015. Lancet Respir Med 2017;5:691-706.

2. India State-Level Disease Burden Initiative CRD Collaborators. The burden of chronic respiratory diseases and their heterogeneity across the states of India: The Global Burden of Disease Study 1990-2016. Lancet Glob Health 2018;6:e1363-74.

3. de Boer AH, Gjaltema D, Hagedoorn P, Frijlink HW. Can 'extrafine' dry powder aerosols improve lung deposition? Eur J Pharm Biopharm 2015;96:143-51.

4. Hou S, Wu J, Li X, Shu H. Practical, regulatory and clinical considerations for development of inhalation drug products. Asian J Pharmaceutical Sci 2015;10:490-500.

5. Sterk PJ, Plomp A, van de Vate JF, Quanjer PH. Physical properties of aerosols produced by several jet- and ultrasonic nebulizers. Bull Eur Physiopathol Respir 1984;20:65-72.

6. Kesser KC, Geller DE. New aerosol delivery devices for cystic fibrosis. Respir Care 2009;54:754-67.

7. Chougule MB, Padhi BK, Jinturkar KA, Misra A. Development of dry powder inhalers. Recent Pat Drug Deliv Formul 2007;1:11-21.

8. Newman SP, Busse WW. Evolution of dry powder inhaler design, formulation, and performance. Respir Med 2002;96:293-304.

9. de Boer AH, Hagedoorn P, Hoppentocht M, Buttini F, Grasmeijer F, Frijlink HW. Dry powder inhalation: Past, present and future. Expert Opin Drug Deliv 2017;14:499-512.

10. Atkins PJ. Dry powder inhalers: An overview. Respir Care 2005;50:1304-12.

11. Lavorini F, Pistolesi M, Usmani OS. Recent advances in capsule-based dry powder inhaler technology. Multidiscip Respir Med 2017;12:11.

12. Thorat S, Mahajan T, Meshram S. Formulation and product devlopment of dry powder inhaler: An overview. World J Pharm Pharm Sci. 2015;4:639-55.

13. Usmani OS, Biddiscombe MF, Barnes PJ. Regional lung deposition and bronchodilator response as a function of beta2-agonist particle size. Am J Respir Crit Care Med 2005;172:1497-504.

14. Demoly P, Hagedoorn P, de Boer AH, Frijlink HW. The clinical relevance of dry powder inhaler performance for drug delivery. Respir Med 2014;108:1195-203.
15. Virchow JC, Crompton GK, Dal Negro R, Pedersen S, Magnan A, Seidenberg J, et al. Importance of inhaler devices in the management of airway disease. Respir Med 2008;102:10-9.

16. Bonini M, Usmani OS. The importance of inhaler devices in the treatment of COPD. COPD Res Practice 2015;1:9.

17. Usmani OS. Treating the small airways. Respiration 2012;84:441-53.

18. Leach C. Targeting inhaled steroids. Int J Clin Pract Suppl 1998;96:23-7.

19. Leach CL. Improved delivery of inhaled steroids to the large and small airways. Respir Med 1998;92 Suppl A: 3-8.

20. Leach CL. Relevance of radiolabeled steroid inhalation studies to clinical outcomes. J Aerosol Med 1998;11 Suppl 1:S29-34.

21. Peng T, Lin S, Niu B, Wang X, Huang Y, Zhang X, et al. Influence of physical properties of carrier on the performance of dry powder inhalers. Acta Pharm Sin B 2016;6:308-18.

22. Busse WW, Brazinsky S, Jacobson K, Stricker W, SchmittK, Vanden Burgt J, et al. Efficacy response of inhaled beclomethasone dipropionate in asthma is proportional to dose and is improved by formulation with a new propellant. J Allergy Clin Immunol 1999;104:1215-22.

23. Laube BL, Janssens HM, de Jongh FH, Devadason SG, Dhand R, Diot $\mathrm{P}$, et al. What the pulmonary specialist should know about the new inhalation therapies. Eur Respir J 2011;37:1308-31.

24. Usmani OS, Biddiscombe MF, Nightingale JA, Underwood SR, Barnes PJ. Effects of bronchodilator particle size in asthmatic patients using monodisperse aerosols. J Appl Physiol (1985) 2003;95:2106-12.

25. Ali M. Effects of three dry powder inhalers on deposition of aerosolized medicine in the human oral-pharyngeal-laryngeal regions. J Drug Des Res 2015;2:1009-15.

26. Rachelefsky GS, Liao Y, Faruqi R. Impact of inhaled corticosteroid-induced oropharyngeal adverse events: Results from a meta-analysis. Ann Allergy Asthma Immunol 2007;98:225-38.

27. Dekhuijzen PNR, Batsiou M, Bjermer L, Bosnic-Anticevich S, Chrystyn H, Papi A, et al. Incidence of oral thrush in patients with COPD prescribed inhaled corticosteroids: Effect of drug, dose, and device. Respir Med 2016;120:54-63.

28. Price D, Keininger DL, Viswanad B, Gasser M, Walda S, Gutzwiller FS. Factors associated with appropriate inhaler use in patients with COPD-lessons from the REAL survey. Int J Chron Obstruct Pulmon Dis 2018;13:695-702.

29. Samec T, Amaechi BT, Battelino T, Krivec U, Jan J. Influence of anti-asthmatic medications on dental caries in children in Slovenia. Int J Paediatr Dent 2013;23:188-96.

30. Levy ML, Dekhuijzen PN, Barnes PJ, Broeders M, Corrigan CJ, Chawes BL, et al. Inhaler technique: Facts and fantasies. A view from the Aerosol Drug Management Improvement Team (ADMIT). NPJ Prim Care Respir Med 2016;26:16017.

31. Vanden Burgt JA, Busse WW, Martin RJ, Szefler SJ, Donnell D. Efficacy and safety overview of a new inhaled corticosteroid, QVAR (hydrofluoroalkane-beclomethasone extrafine inhalation aerosol), in asthma. J Allergy Clin Immunol 2000;106:1209-26.

32. Imai E, Hatae K, Shimada A. Oral perception of grittiness: Effect of particle size and concentration of the dispersed particles and the dispersion medium. J Texture Stud. 1995;26:561-76.

33. Engelen L, de Wijk RA, van der Bilt A, Prinz JF, Janssen AM, Bosman F. Relating particles and texture perception. Physiol Behav 2005;86:111-7.

34. Tyle P. Effect of size, shape and hardness of particles in suspension on oral texture and palatability. Acta Psychol (Amst) 1993;84:111-8. 